\title{
ПОЛУЧЕНИЕ СЛОЯ МИКРОКРИСТАЛЛОВ ПЕРЕХОДНЫХ МЕТАЛЛОВ НА АНОДИРОВАННОЙ ПОВЕРХНОСТИ АЛЮМИНИЯ
}

\author{
О.М. Турсункулов ${ }^{1}$, Э.М. Ибрагимова ${ }^{1}$, Н.Э. Искандаров ${ }^{1}$, С.Э. Улугмурадов ${ }^{1}$, \\ Х.Т. Юсупов ${ }^{1}$, М. Баиев ${ }^{2}$, М.А. Махмудов ${ }^{2}$ \\ ${ }^{1}$ Центр передовых технологий при Министерстве инновационного развития РУз, Талабалар \\ шахарчаси 3a, 100174, Ташкент, Узбекистан; oybtm09@gmail.com \\ ${ }^{2}$ Физико-технический институт АН РУз, Ташкент, Узбекистан \\ (Получена 10.01.2020)
}

\begin{abstract}
Ушбу ишда электрокимёвий усулида олинган порали алюминий оксиди уурганилган. Ушбу жараён алюминий оксидни суюлтирилган щавель ва ортофосфор кислоталарда хєосил бўлиши, хсамда оксидни эришга боғлиқ эканлиги кўрсатилди. Анодланган алюминий оксид таглик устига мисс ва никель нанотузилмали қєатламларни термик вакуум орқ̨али хєосил қุилинди. Катламда хєосил бўлган мисс ва никель нанотузилмали доначаларнинг тузилиши анодланган алюминий оксид пораларига боғликелиги аникчланди. Намуналар морфологияси, элемент тахплли ва кристалл структураси сканерловчи электрон микроскоп ва рентгенфазавий диффрактометр оркали аникчланди.

В работе изучено формирование пористого слоя оксида алюминия на поверхности алюминия электрохимическим методом в процессе образования и растворения оксида в водных растворах щавелевой и ортофосфорной кислот. На полученной подложке анодированного оксида алюминия были синтезированы микроразмерные структуры меди и никеля путем вакуумного осаждения. Морфология поверхности, элементный состав и кристаллическая структура полученных образцов были анализированы при помощи сканирующего электронного микроскопа и рентгеновского дифрактометра.
\end{abstract}

The formation of the porous aluminum oxide on surface by the electrochemical method was investigated. This phenomenon is associated with simultaneous processes of formation and dissolution of the aluminum oxide in aqueous solutions of oxalic and phosphoric acids., The nanosized structures of copper and nickel films were synthesized on the anodized aluminum oxide using vacuum deposition. The dependence of the formation of granular nickel and copper films on the porous surface of aluminum oxide was found. The morphology, element composition and crystal structure of the samples were measure using a scanning electron microscope and an X-ray diffractometer.

\section{I. ВВЕДЕНИЕ}

В настоящее время большое внимание исследователей уделяется исследованию и разработке технологии получения наноструктурированных материалов [1, 2]. Наиболее эффективные способы получения наноструктур металлов и оксидов основаны на процессах самоорганизации. Наноструктуры широко применяются в качестве сенсоров [3], магнитных носителей [4], оптических преобразователей [5], особенно, катализаторов [6-9]. Следует отметить, что получение пористых структур оксида алюминия в процессе анодного окисления алюминия является одним из наиболее широко используемых методов, суть которого заключается в анодировании оксида металла в электролитах в условиях действия электрического поля с образованием пор в процессах образования и растворения оксида [10-13]. Наибольшее применение пористые пленки оксида алюминия нашли в качестве матриц для синтеза упорядоченных 
массивов анизотропных наноструктур различного состава [14], например, металлических и полупроводниковых нанопроволок на относительно больших площадях $\left(>1 \mathrm{~cm}^{2}\right)$, т.е. выбор осаждаемого в поры материала практически не ограничен. Используются следующие методы осаждения микрокатализаторов: плазмохимичский синтез [15], газофазный [16], металло-органический [17], гальванический [18]. Анизотропные металло-оксидные наноструктуры имеют большую удельную площадь поверхности, что особенно важно для нанесения каталитически активных переходных металлов. Соответственно для улучшения сцепления необходимо использовать подложку, имеющую значительную удельную поверхность за счет шероховатости или пористости и придающую катализатору более высокую эффективность и жесткость [19-22]. Поэтому получение равномерной поликристаллической пленки переходного металла на большой площади является актуальной проблемой [23]. Целью работы является получение анодированной пористой поверхности алюминия и синтез слоя микрокристаллов переходных металлов.

\section{II. ЭКСПЕРИМЕНТ}

Материалы. Для изготовления подложки использована промышленная фольга алюминия толщиной 500 мкм. Для синтеза металла на ее поверхности использованы прутки сплава никеля и меди. Выбор этих переходных металлов обусловлен тем, что они широко применяются в качестве катализаторов для паровой конверсии метана, гидрокрекинга и гидросульфиризации [24]. Эти переходные металлы имеют высокие значения работы выхода $\left(\varphi_{\mathrm{Ni}}=5.6\right.$ эВ; $\varphi_{\mathrm{Cu}}=$ 4.55 эВ), первый потенциал ионизации равен $J_{\mathrm{Ni}}=7.6$ эВ, $\left.J_{\mathrm{Cu}}=7.7 э \mathrm{~B}\right)$, для никелиевых катализаторов процент $d$ характера связи - 40\% [25].

Методы и оборудование. Пористую подложку из оксида алюминия изготовили известным методом [10-11] анодного окисления алюминия (АОА) в двухэлектродной электрохимической ячейке с использованием источника постоянного тока. Схема электрохимической ячейки для анодирования представлена на рис. 1(a). Образцы (Al-фольга) закрепляли с помощью резинового уплотнителя на медную подставку, которая одновременно с функцией механического зажима образца служила в качестве токоотводного анода. Поверх закрепленного образца устанавливали тефлоновый стакан, являющийся корпусом электрохимической ячейки. В качестве катода использовали графитовый стержень. Электролит в процессе анодирования непрерывно перемешивали мешалкой, а пониженная температура поддерживалась с помощью охлаждаемой камеры, где находилась установка. Процесс анодирования включает несколько стадий (рис 1(б)).

1 стадия. Вначале поверхность Al-фольги очищали с помощью этилового спирта в ультразвуковой ванне, затем Al подложку подвергали рекристаллизационному отжигу на воздухе при температуре до $400^{\circ} \mathrm{C}$ в течение 3 часов для роста слоя оксида металла в воздухе. Размер зерен $\mathrm{Al}$ после отжига увеличивался в зависимости от температуры обработки.

2 стадия. Термообработанную фольгу помещали в электрохимическую ячейку с раствором 0.3-0.6 М щавелевой кислоты $(\mathrm{COOH})_{2}$. При этом температуру поддерживали в интервале от $(5 \pm 1)^{\circ} \mathrm{C}$ до комнатной, статическое напряжение 20-60 Вольт подавали в течение 120 минут. 


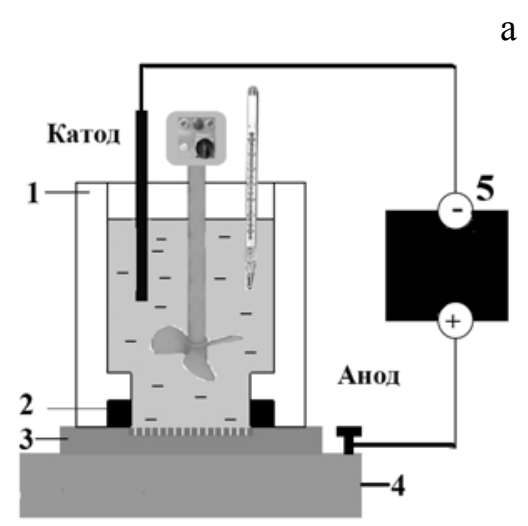

a

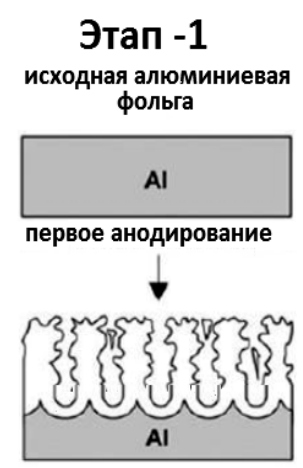

b

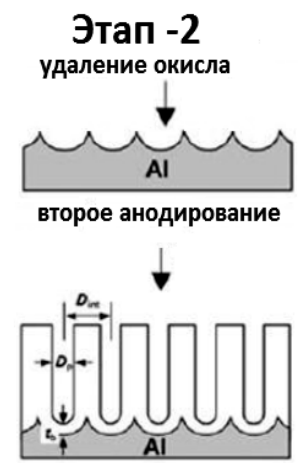

Рис. 1. Изображение двухэлектродной электрохимической ячейки, применяемой для анодного окисления алюминия $(a)$ : 1 - тефлоновый стакан, 2 - резиновый уплотнитель; 3 Al-фольга (образец); 4 - медная платформа. Механизм формирования пористого анодного окисления алюминия $(b)$.

Алюмооксидную пленку, образовавшуюся в процессе анодирования на поверхности $\mathrm{Al}$, селективно растворяли в смеси травления $\mathrm{CrO}_{3} / \mathrm{H}_{3} \mathrm{PO}_{4}$ при комнатной температуре.

3 стадия. Полученные в результате поверхности с неупорядоченной шероховатостью подвергали повторному анодному окислению в тех же условиях. Скорость роста пленки в указанных выше условиях анодирования составляла приблизительно 1 мкм/час.

4 стадия. Затем фольгу промывали этанолом и высушивали на воздухе. В результате на поверхности Al-фольги получаем слой оксида алюминия с неупорядоченной пористостью от 500 нм до 10 мкм, который, в принципе, может служить подложкой для нанесения слоя металла. Исследование морфологии поверхности (микроструктуры анодированного алюминия и напыленного слоя металлов) осуществляли в сканирующем электронном микроскопе (СЭМ) EVO MA 10 (Zeiss, Германия). Полученные образцы (до и после анодирования и напыления металла) крепили электропроводящим скотчем на предметный столик из металлического сплава и помещали в вакуумную камеру микроскопа. На филамент подавали ускоряющее напряжение до 20 кВ. Был использован детектор вторичных электронов SE (secondary electrons), рабочее расстояние WD (working distance) составляло 8.5 мм. Изображения поверхности были получены в масштабах 100, 10 и 1 мкм. Локальный элементный состав поверхности определяли с помощью энергодисперсионного анализатора марки EDS (Oxford Instrument) - Aztec Energy Advanced X-actSDD. Рентгенофазовый анализ анодированного слоя оксида алюминия и нанесенного покрытия никеля или меди выполняли при комнатной температуре на рентгеновском дифрактометре Empyrean (PANalytical), оснащенном $\mathrm{Cu}$-трубкой $\left(K_{a} 1=1.5406 \AA \hat{)}\right)$ и детектором Pixel 1D Detector, в интервале углов $2 \theta$ от $5^{\circ}$ до $90^{\circ}$ в режиме сканирования с шагом 0.013 градуса и временем накопления сигнала в точке 5 с. Для технологии нанесения тонких пленок выбран метод вакуумного напыления переходных металлов на пористую подложку, так как, в отличие от электрохимического осаждения, он дает возможность получения равномерной поликристаллической пленки переходного металла на большой 
площади. Был использован вакуумный пост для термического напыления. На первом этапе была отработана технология нанесения слоя меди на полированную поверхность стекла. В первый момент распыления выгорают органические соединения на испарителе металла, от попадания которых на напыляемую поверхность защищает магнитная заслонка, управляемая снаружи. Затем Al-фольгу размером $5 \times 10$ см с поверхностным слоем пористого оксида алюминия помещали на металлическую подложку, закрытую по окружности кварцевой трубкой. Был использован специальный испаритель площадью $7 \times 5$ мм из никель-медной проволоки диаметром 0.8 мм, который устанавливали на молибденовую лодочку. Вся конструкция закрывалась вакуумным колпаком. Процесс осаждения металла на оксид алюминия проводили в вакууме $\left(\sim 10^{-5}-10^{-6}\right.$ торр) в течение 60 сек. В результате толщина напыленного слоя никель-медной пленки составляла $\sim 100$ нм.

\section{III. РЕЗУЛЬТАТЫ И ОБСУЖДЕНИЕ}

На рис. 2 представлена микроструктура исходной алюминиевой фольги до и после термической обработки. Как видно из рис. 2(а), поверхность исходной фольги алюминия неоднородна (изображение получено в масштабе 10 мкм). На всех участках поверхности присутствуют полосы проката различной ширины, поверхностные вкрапления, которые, возможно, возникли в технологическом процессе. Поэтому перед началом процесса анодирования была проведена термообработка при $400^{\circ} \mathrm{C}$ для сглаживания шероховатости и формирования оксидного слоя. Рис. 2(b, c) показывает, что поверхность образца стала однородной, видимые крупные вкрапления и дефектные полосы исчезли после проведения
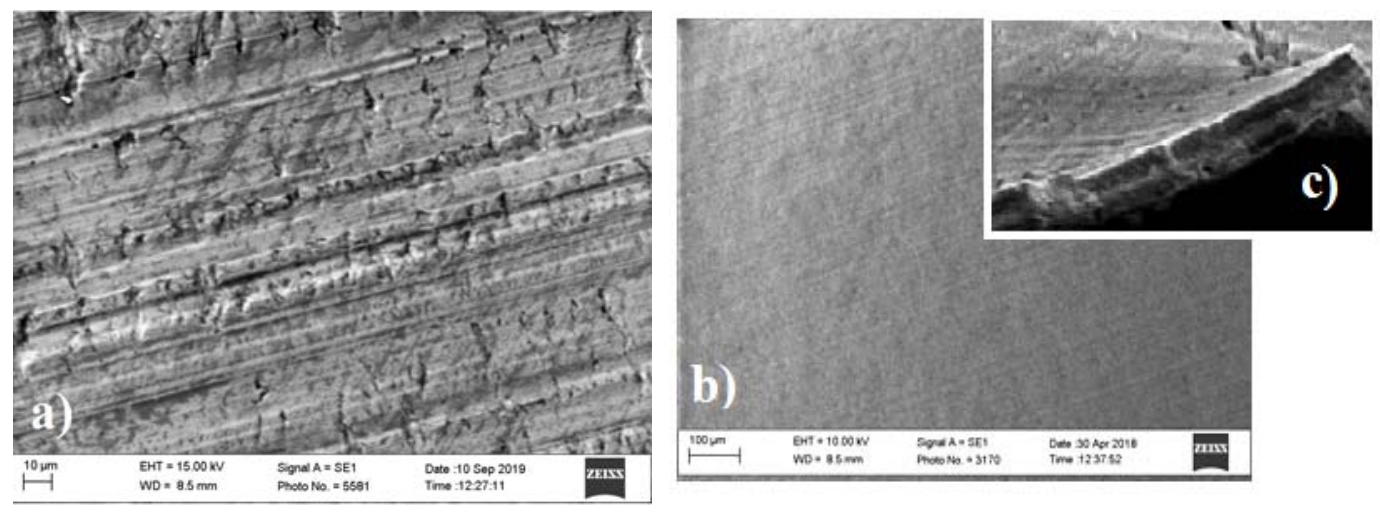

Рис. 2. Изображения поверхности при разных увеличениях СЭМ: исходная алюминиевая фольга (a); после термического отжига при температуре $400^{\circ} \mathrm{C}(b)$; поперечное сечение $(c)$.

термообработки, но в некоторых образцах остались незначительные полосы проката. В целом, такая термообработка дает оптимальную поверхность алюмооксида для проведения анодирования, в процессе которого происходит миграция анионов с границы электролит-окись алюминия сквозь термическую оксидную пленку к границе алюминий-оксид, где формируется новый оксидный слой. После первого анодного окисления на поверхности $\mathrm{Al}$ формируется барьерный слой оксида, который растворяли в смеси $\mathrm{CrO}_{3}-\mathrm{H}_{3} \mathrm{PO}_{4}$ при $22^{\circ} \mathrm{C}$ с 
последующей промывкой и сушкой. Морфология полученной после травления поверхности показана на рис. 3(a, b) в масштабе 10 мкм и 100 мкм.
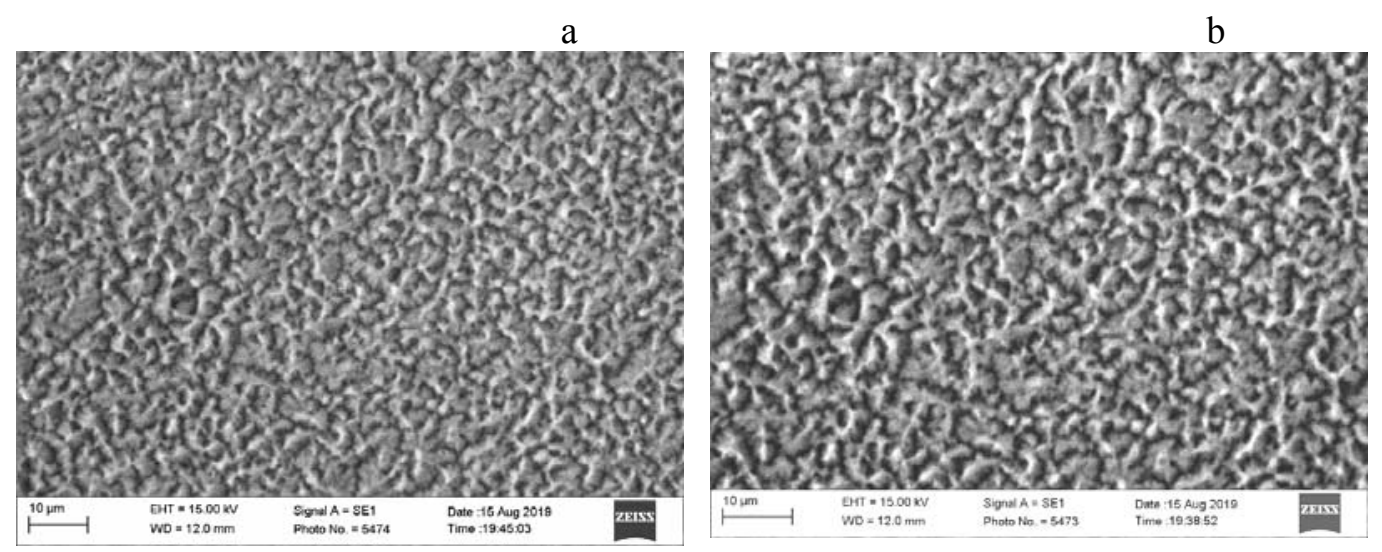

Рис. 3. Поверхностная микроструктура пленок оксида алюминия после проведения первого анодирования в растворе щавелевой кислоты.

Видны микропоры, которые неоднородны по форме, расположены хаотически и имеют большой разброс по поверхности. Как видно из рисунка, после первого анодирования наблюдается неравномерный рост окисла на алюминиевой фольге. Однако в результате сил отталкивания между соседними порами в ходе длительного первого окисления происходит самоупорядочение пористой структуры. В результате на границе раздела оксид-металл образуется периодическая структура с равномерными порами.

Затем был проведен второй этап анодирования при тех же условиях, что и первый. На рис. 4 наблюдается более равномерное распределение пор по всей поверхности образца, чем после первого этапа (рис. 3). Средний размер пористой структуры находится в пределах $500 \mathrm{~nm}-1$ мкм. Данные элементного анализа показывают максимальное значение содержания алюминия, достигающего $98.3 \%$ и незначительное количество кислорода в приповерхностном слое $~ 1 \%$.
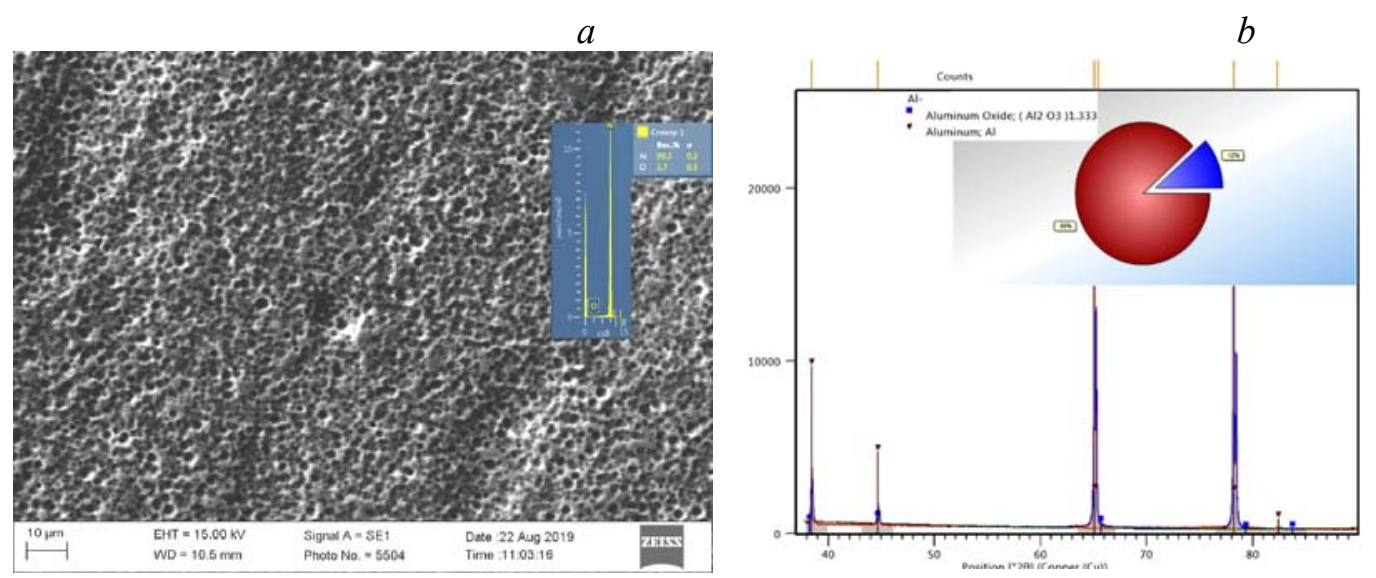

Рис. 4. Поверхностная микроструктура (SEM) при шкале 10 мкм, локальный элементный анализ пленок (EDS) оксида алюминия, XRD рентгенограмма после второго анодирования. 
Таким образом, изучено явление образования пор в оксиде алюминия, происходящее в водных растворах серной, щавелевой кислот электрохимическим методом. Были определены оптимальные условия проведения электрохимического анодирования для получения на поверхности плотноупакованных равномерных пор. Показано, что проведение второго анодирования ведет к растворению приповерхностного барьерного слоя и формированию нанопористой структуры оксида алюминия. Затем на поверхность пористой пластины алюминия наносили слои никеля и меди методом вакуумного напыления. Толщина напыленной никельмедной пленки составляет $\sim 100$ нм. Морфология поверхности термически напыленной пленки показала равномерно распределенную никель-медную микроструктуру на пористом алюминии. Заметного дефектообразования на поверхности пор не происходило. Однако по поверхности образцов наблюдалась мелкозернистая кристаллизация с размером микрокристаллитов менее 1 мкм. На рис. 5 и 6 представлены полученые данные элементного и фазового анализа.
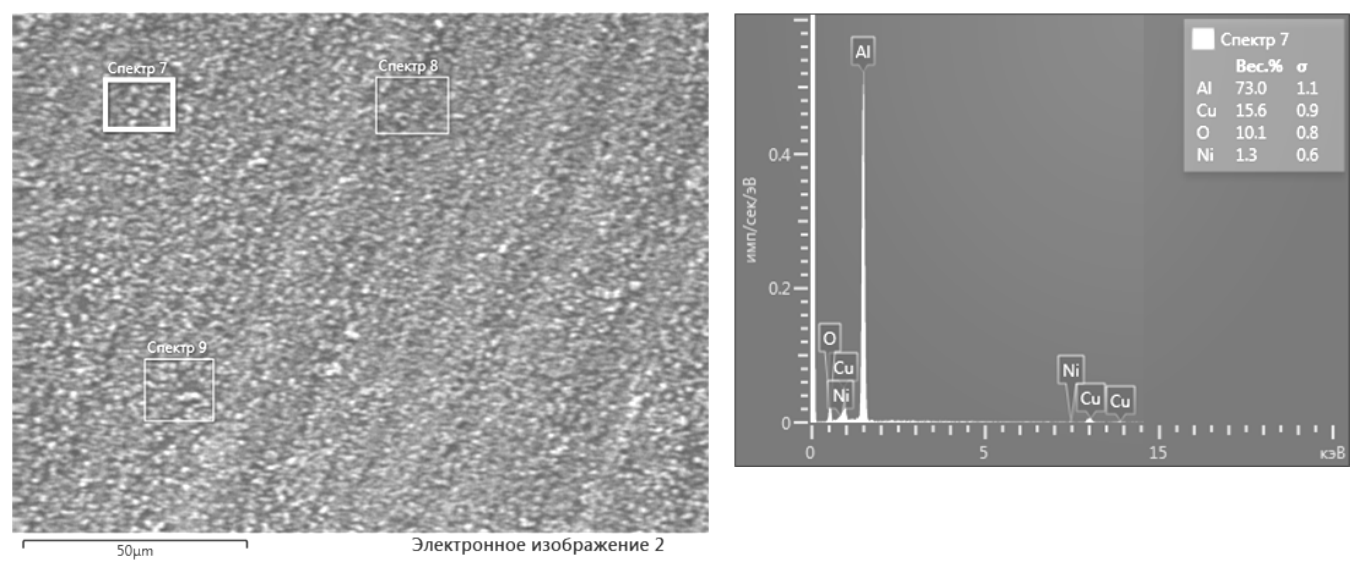

Рис. 5. Изображения СЭМ и данные элементного анализа анодированной пористой пленки алюминия, на поверхность которой методом термического напыления наносили слои меди и никеля.
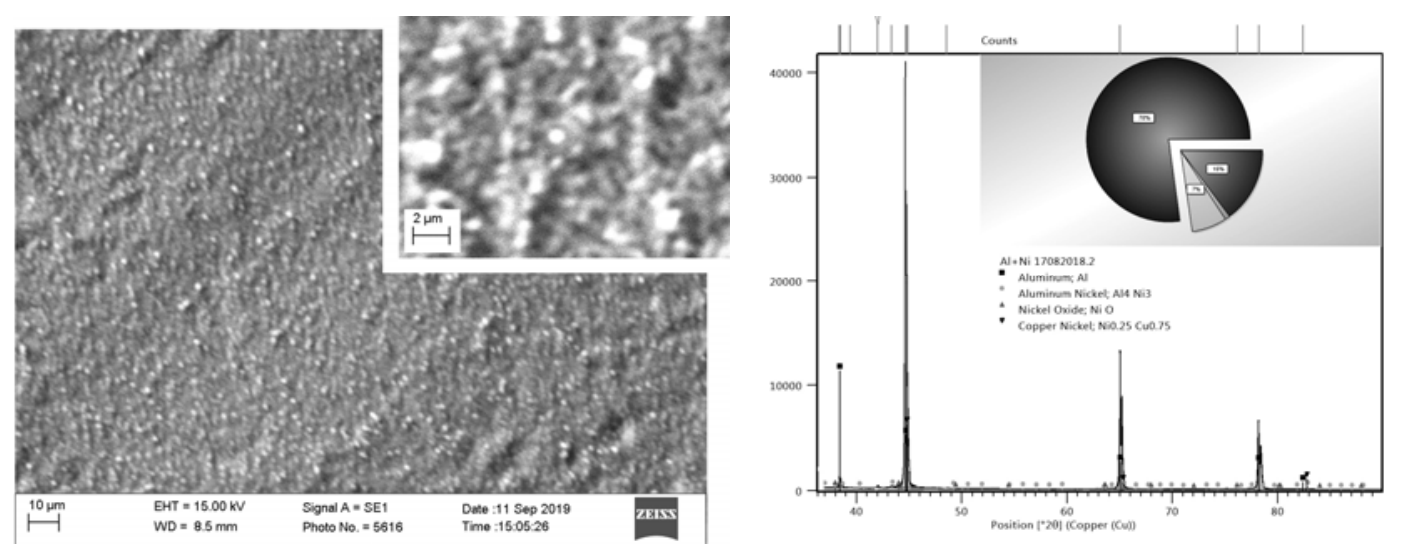

Рис. 6. Изображение SEM/EDS и анализ рентгенограммы анодированной пористой пленки алюминия после анодного окисления с последующим осаждением никель-медного сплава. 
Локальный элементный анализ поверхности образцов показывает следующее соотношение исходных компонентов. Основную часть составляет алюминий и его оксид, имеющий атомный вес до 73\%, при этом содержание меди варьируется от 15 до 5 ат.\%. Далее наименьшее значение, определенное-дисперсионным элементным анализатором, имеет никель с содержанием до 1 ат.\%. Рентгенофазовый анализ показывает, что в дифракционной картине анодированного алюминия присутствуют фазы сплавов оксида никеля и меди с никелем (рис. 6). Эти металлы имеют близкую пространственную группу симметрии и являются основными компонентами образцов. Присутствуют также пики, принадлежащие фазе оксидов никеля и фазе никель-медь.

\section{IV. ЗАКЛЮЧЕНИЕ}

В данной работе представлены исследования процессов анодного окисления алюминиевой фольги. Проведен подбор условий анодирования для получения заданных размеров и распределения пор. На полученной подложке анодированного оксида алюминия проведен синтез наноразмерных структур на основе меди и никеля с помощью термического вакуумного напыления. Измерение морфологии и кристаллической структуры полученных образцов проведены с помощью сканирующего электронного микроскопа и рентгеновского дифрактометра. Сканирующая электронная микроскопия поверхности позволила визуализировать полученную структуру и определить характерные размеры пор, диаметр которых составил до 500 нм, что дает возможность идентифицировать их как нанообразования на поверхности оксида алюминия. На поверхность анодированного алюминия методом вакуумного осаждения был нанесен слой никеля и меди толщиной до 1 мкм. Показано образование мелкозернистиых соединений на участках с наличием круглых пор. При этом обнаружена связь формирования зернистости пленок никеля от пористости поверхности оксида алюминия. Рентгенофазовый (рентгеновский дифрактометр) и элементный анализ (сканирующий электронный микроскоп) образцов анодированного алюминия, полученных химическим синтезом, показали, что в обоих случаях наблюдается формирование многофазного покрытия алюминия, никеля и других компонентов.

Работа выполнена в рамках проекта ПЗ-2017092438 «Разработка технологии получения наноструктурированных катализаторов на основе переходных металлов и их оксидов».

\section{ЛИТЕРАТУРА}

1. A.I. Gusev, A.A. Rempel. Nanocrystalline Materials (monograph) (Cambridge, Cambridge International Science Publishing, 2004).

2. Andrew M. Collins. Nanotechnology Cookbook. Practical, Reliable and Jargon-free Experimental Procedures. First edition (Elsevier Science, ISBN: 978-0-08-097172-8, 2012. DOI: https://doi.org/10.1016/C2010-0-69558-7.

3. Keerthy Dhara Roy, Mahapatra Debiprosad, Analytical Biochemistry 586, 113415 (2019).

4. Lei Xiea, Anding Wang, Qiang Li, Xinmin Wang, Chain-Tsuan Liu, Journal of Magnetism and Magnetic Materials 483, 158-163 (2019).

5. Z.M.E.Vorathin, I. Hafiz, N. Ismail, M. Loman, Optics \& Laser Technology 121, 105841 (2020).

6. Ю.В. Попов, В.М. Мохов, Д.Н. Небыков, И.И. Будко, Известия Волг. ГТУ, Часть 1, стр.5-44. 
7. Baolin Zhu, Xiaoxiang Zhang, Shurong Wang, Microporous and Mesoporous Materials 102, 333-336 (2007).

8. F. Patcas, W. Krysmann, Applied Catalysis: A General 316, № 2, 240-249 (2007).

9. В.Н. Ефремов, Е.3. Голосман, Кинетика и катализ 47, № 5, 805-817 (2006).

10. Л.А. Носова. Синтез и исследование электрофизических и теплофизических свойств наноструктур на основе пористого оксида алюминия и тонких пленок $\mathrm{ZnO}$. Диссертация на соискание ученой степени к.-ф.м. н. (Ташкент, 2005).

11. Woo Lee. Application of Anodic Aluminum Oxide (AAO) as a Template to the Development of Novel Nanostructured Materials. Ph.D. Dissertation (Seoul National University, South Korea, 2003).

12. Ming Wena, Yanqiong Li, Junmin Zhang, Weiming Guan, Applied Surface Science 257, 4836-4843 (2011).

13. G. Patermarakis and H.S. Karayannis, Electrochimica Acta 40, 2647-2656 (1995).

14. H. Masuda, F. Hasegwa, and S. Ono, J. Electrochem. Soc. 144, 127-130 (1997).

15. Т.Н. Миллер, Изв. АН СССР: Неорганические материалы 15, № 4, 557-562 (1979).

16. Hossein Rasoulnezhad, Ghassem Kavei, Kamran Ahmadi, Mohammad Reza Rahimipour, Applied Surface Science 408, 1-10 (2017).

17. H. Hahn, R.S. Averback, Journal of Applied Physics 67, 1113-1115 (1990).

18. Zhaojie Wang, Nuo Yu, Xuan Li, Wanjian Yu, Shilong Han, Xiaoling Ren, Zhigang Chen, Chemical Engineering Journal 381, 122613 (2020).

19. И.В. Лукиянчук, Л.М. Тырина, В.С. Руднев, А.Ю. Устинов, П.М. Недозоров, М.С. Васильева, Кинетика и катализ 49, № 3, 461-467 (2008).

20. F. Patcas, W. Krysmann, Applied Catalysis A: General 316, № 2, 240-249 (2007).

21. H. Huang, Y. Xu, Q. Feng, D.Y.C. Leung, Catalysis Science \& Technology 5, 2649-2669 (2015).

22. J. Li, H. Chang, L. Ma, J. Hao, R.T. Yang, Catalysis Today 175, 147-156 (2011).

23. У.М. Джемилев, Н.Р. Поподько. Металлокомплексный катализ в органическом синтезе (Москва, Химия, 1999); ISBN 5-7245-0987-3.

24. О.В. Крылов. Гетерогенный катализ. Учебное пособие для вузов (Москва, Академкнига, 2004).

25. Ч. Сеттерфилд. Практический курс гетерогенного катализа. Перевод с англ. (Москва, Мир, 1984). 